\title{
CHANGES IN BIOMECHANICAL PARAMETERS DURING HEART PERFUSION AND AFTER MIDAZOLAM PRE-MEDICATION - EXPERIMENTAL PILOT STUDY
}

\author{
Lenka Bartosikova $^{a *}$, Jiri Necas ${ }^{\mathrm{a}}$, Tomas Bartosik ${ }^{\mathrm{b}}$, Petr Frana ${ }^{\mathrm{c}}$, Martin Pavlik ${ }^{\mathrm{b}}$
}

\author{
a Department of Physiology, Faculty of Medicine and Dentistry, Palacky University, 77515 Olomouc, Czech Republic \\ ${ }^{b}$ Department of Anaesthesiology and Intensive Care, St. Anne's University Hospital Brno, Czech Republic \\ c $2^{\text {nd }}$ Department of Internal Medicine, St. Anne's University Hospital Brno, Czech Republic \\ e-mail:bartosil@tunw.upol.cz
}

Received: February 15, 2008; Accepted (with revisions): April 25, 2008

Key words: Heart ischemia-reperfusion/Midazolam

Background: Midazolam is a frequently used benzodiazepine in anaesthesiology and intensive care.

Aim: The aim of pilot study was to monitor its effect during heart perfusion in the laboratory rat.

Methods: The same groups of animals $(n=10)$. The $1^{\text {st }}$ group was treated with midazolam in a dose of $0.5 \mathrm{mg} / \mathrm{kg}$ i.p. The $2^{\text {nd }}$ group was a placebo. After i.p. administration of heparine injection of $500 \mathrm{IU}$ dose, the hearts were excised and perfused (modified Langendorf's method). Working schedule: stabilization/ischaemia/reperfusion proceed at intervals of 20/30/60 min. Monitored parameters in isolated heart: left ventricle pressure (LVP), end-diastolic pressure (LVEDP), contractility $\left(+\mathrm{dP} / \mathrm{dt}_{\max }\right)$.

Results: The treated hearts showed improved postischemic recovery, reaching LVP values of $92 \pm 6 \%$ at the end of the reperfusion, placebo only $61 \pm 7 \%$. In placebo hearts LVEDP rose from $10.0 \pm 0.5 \mathrm{mmHg}$ to $43 \pm 4 \mathrm{mmHg}$ after, in treated animals only about $25 \mathrm{mmHg}$. The treated hearts improved $+\mathrm{dP} / \mathrm{dt}_{\text {max }}$ recovery during reperfusion to $91 \pm$ $8 \%$. These values were significantly greater than those obtained from the placebo hearts.

Conclusions: Positive changes in monitored parameters were found in this experimental pilot study. We conclude that the administration of midazolam in laboratory rats has a cardioprotective potential against ischemia-reperfusion induced injury.

\section{INTRODUCTION}

Midazolam is a benzodiazepine derivative. It has powerful anxiolytic, amnestic, hypnotic, anticonvulsant, skeletal muscle relaxant and sedative properties. It is considered a fast-acting benzodiazepine, with a short elimination half-life. It is therefore a very useful drug to use for short minor procedures such as dental extraction. Midazolam was first synthesized in 1976 by Fryer and Walser ${ }^{1}$.

Like other benzodiazepines, midazolam acts on benzodiazepine receptors to enhance the binding of GABA to the $\mathrm{GABA}_{\mathrm{A}}$ receptor which results in inhibitory effects on the central nervous system ${ }^{2}$.

Midazolam is indicated for the acute management of aggressive or delirious patients and also is sometimes used for the acute management of seizures such as status epilepticus. Long term use for the management of epilepsy is not recommended however, due to the significant risk of tolerance which renders midazolam and other benzodiazepines ineffective and as well the significant side-effect of sedation ${ }^{3}$. In mice given chronic midazolam a slowly evolving tolerance developed to the anticonvulsant properties of midazolam over 15 days, although some anticonvulsant effects were still apparent after 15 days of continued administration ${ }^{4}$.

Midazolam is occasionally used as a hypnotic, especially in hospitals. Like other benzodiazepines, it produces a decrease in delta activity, though the effect of benzodiazepines on delta may not be mediated via benzodiazepine receptors. Delta activity is an indicator of depth of sleep within non-REM sleep; it is thought to reflect sleep quality, with lower levels of delta sleep reflecting poorer sleep. Thus midazolam and other benzodiazepines cause deterioration in sleep quality. Cyproheptadine may be superior to nitrazepam in the treatment of insomnia as it enhances sleep quality based on EEG studies ${ }^{5}$.

Midazolam is frequently used benzodiazepine in anaesthesiology and intensive care, too.

The aim of the study was to monitor the effects of midazolam during heart perfusion of laboratory rat.

\section{METHODS}

The study and its experimental protocol were approved and monitored by the Ethics Committee of Palacký University. The state of health of all animals was inspected regularly several times a day both during the acclimation of the animals and in the course of the whole experiment performed by the working group whose members are holders of the Eligibility Certificate issued by the Central Commission for Animal Protection pursuant to Section 17 of the Czech National Council Act No 246/1992 Coll. on animal protection against maltreatment.

This study was performed on 20 male Wistar SPF (AnLab, Germany) laboratory rats of the same age ( 6 months) and comparable weight (345 \pm 15 gr). The 
animals were housed in a standard controlled temperature, fed the standard diet for small laboratory animals, and given water ad libitum. After a recovery period, the animals were divided randomly into 2 groups $(n=10)$.

The first group - treated group - received midazolam in a single dose $0.5 \mathrm{mg} / \mathrm{kg}$ by i.p. injection. The second group - the placebo group - received only normal saline solution also by i.p. injection.

The rats were anesthetized with an i.p. injection of anaesthetical mixture ( $2 \%$ Rometar $0.5 \mathrm{ml}+1 \%$ Narkamon $10 \mathrm{ml}$, dose $0.5 \mathrm{ml}$ solution/ $100 \mathrm{~g}$ body weight). After the i.p. heparine injection of 500 IU dose, the hearts were excised and perfused. In all experiments, the modified Langendorff method and the universal apparatus Hugo Sachs Electronic UP 100 (Germany HSE) were used. Schedule: stabilization/ischaemia/reperfusion proceeded at intervals of 20/30/60 min. Biomechanical parameters from isolated heart: left ventricle pressure (LVP), enddiastolic pressure (LVEDP), contractility $\left(\mathrm{dP} / \mathrm{dt}_{\max }\right)$ were measured using a ball filled with liquid $(8-12 \mathrm{mmHg}$ ), inserted through the left atrium in the left ventricle connected to the analog convertor (Isotec HSE, DIF modul HSE) ${ }^{6}$.

\section{RESULTS}

See Fig. 1-3.

\section{DISCUSSION}

A variety of laboratory and clinical studies clearly indicate that exposure to anaesthetic agents can lead to a marked protection of the myocardium against ischaemia-reperfusiuon injury. Several changes in the protein structure of the myocardium that may mediate this cardioprotection have been indentified. Ischaemia-reperfusion of the heart occurs in a variety of clinical situations including transplantations, coronary artery bypass grafting and vascular surgery. Ischaemia may also occur during stressful anaesthetic induction. Early restoration of arterial blood flow and measures to improve the ischaemic tolerance of the tissue are the main therapeutic options (i.e. cardioplegia and betablockers). There is increasing evidence that anaesthetic agents interact with the mechanisms of ischaemia-reperfusion injury and protect the myocardium by a preconditioning and postconditioning mechanism $^{7-10}$.

In 1996, specific protection against myocardial reperfusion injury by halothane was described ${ }^{11}$. While all previous studies had been unable to discriminate between anti-ischemic effects and effects against reperfusion injury, this study demonstrated for the first time that modification of the reperfusion conditions by administration of a common volatile anaesthetic specifically reduced reperfusion damage. A similar cardioprotective effect was confirmed for enflurane, isoflurane, sevoflurane and desflurane and the noble gas xenon under a variety of ex-

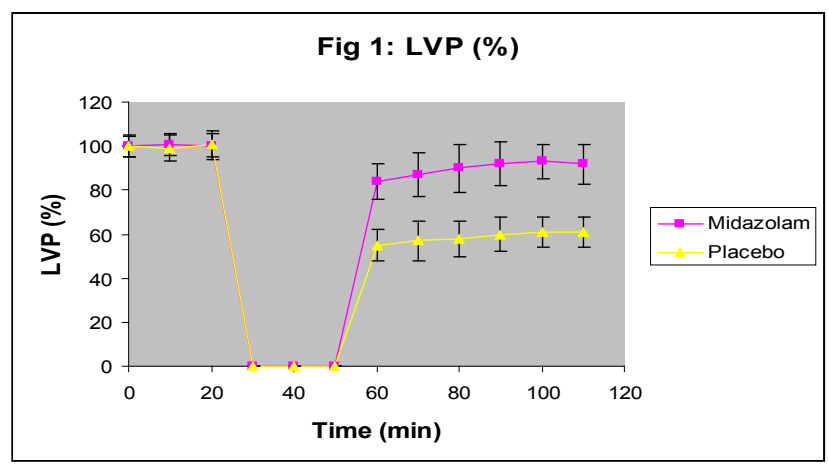

Fig. 1. Left ventricle pressure.

In hearts from placebo animals, LVP recovered up to $61 \pm 7 \%$ of pre-ischemic values at the end of the reperfusion. In the midazolam pretreated animals, the hearts showed significantly better post-ischemic recovery, reaching LVP values of $92 \pm 6 \%$ at the end of the reperfusion.

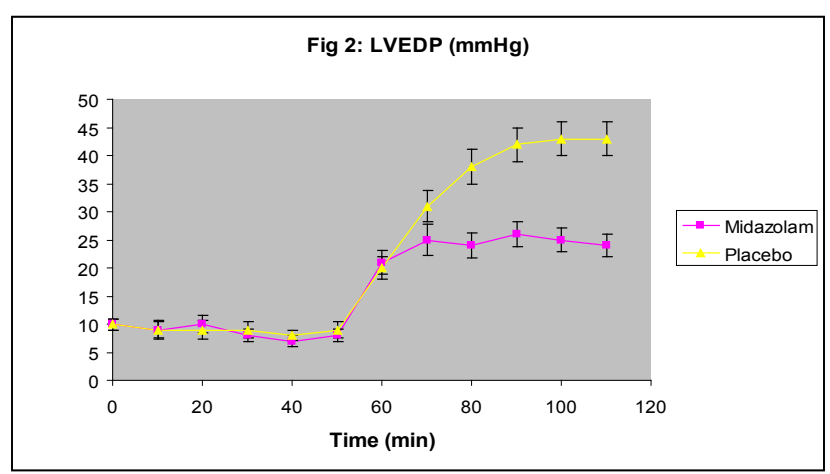

Fig. 2. End-diastolic pressure.

In hearts from placebo animals LVEDP rose from $10.0 \pm 0.5$ to $43 \pm 4 \mathrm{mmHg}$ after $60 \mathrm{~min}$ of reperfusion. This increase was diminished in the hearts from the midazolam pretreated animals at the end of reperfusion.

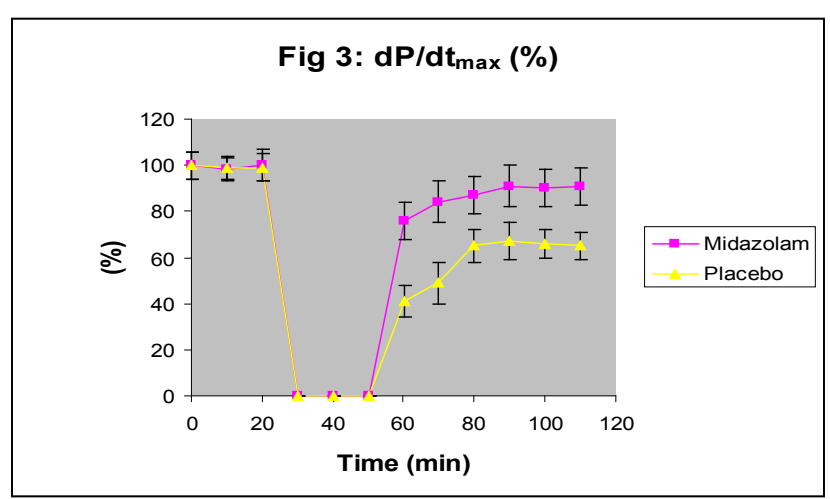

Fig. 3. Contractility.

The pretreatment with midazolam improved $+\mathrm{dP} /$ $\mathrm{dt}_{\max }$ recovery during reperfusion to $91 \pm 8 \%$ after $60 \mathrm{~min}$ of reperfusion. These values were significantly greater than those obtained from placebo hearts. 
perimental conditions in vitro and in vivo; cardioprotection against reperfusion damage was also maintained when the heart was already protected against ischaemic damage by cardioplegic solutions ${ }^{12,13}$.

The benzodiazepines have hardly been investigated for myocardial protection. Whether these intravenous anesthetics interfere with neutrophil-endothelium interaction, $\mathrm{Ca}^{2+}$ influx and free radical production still needs to be elucidated ${ }^{14-18}$. It is known, that peripheral benzodiazepine receptors are present in peripheral tissues such as adrenals, kidney and heart, as well as in the brain ${ }^{19,20}$. The peripheral benzodiazepine receptor is different from the central benzodiazepine receptor, which is coupled to GABA receptors and responsible to the classical sedative, anxiolytic and anticonvulsant effect ${ }^{21,22}$. Peripheral benzodiazepine receptor is a 169-amino acid protein with five trans-membrane domains associated with the mitochondrial outer membrane ${ }^{23,24}$ which has been suggested to be involved in the control of several mitochondrial functions including the respiratory chain and ion channel activities, in the regulation of apoptosis, which occurs during cardiac injury ${ }^{25,26}$ and in the modulation of immune functions, steroidogenesis and neurodegenerative process ${ }^{24,27}$.

Midazolam is extensively used as hypnotic and anesthetic in clinical situations ${ }^{28}$. Midazolam has been reported to impair memory retention at sedative doses in human studies, and retrograde amnesia after recovery from anesthesia with anesthetic doses is often observed in humans ${ }^{29}$. Midazolam is used in pediatric practice too ${ }^{30}$. Midazolam benzodiazepines have not been investigated extensively in the adult population and no references were found in the literature to their myocardial effects in pediatric cardiac surgical patients.

In isolated perfused guinea pig hearts subjected to ischaemia midazolam reduced neutrophil adhesion to nonischaemic control levels. Adhesion of polymorphonuclear neutrophils to the coronary endothelium is a crucial step in the development of ischemic myocardial injury ${ }^{14}$.

Midazolam may interfere with $\mathrm{Ca}^{2+}$ influx and free radical production but the data are contradictory in this respect $^{31}$. In the study of Papaioannou et al. ${ }^{32}$ some interesting anesthetic effects on mitochondrial and sarcolemmal $\mathrm{K}_{\text {ATP }}^{+}$channels were described. This study has showed that barbiturates inhibit mitochondrial $\mathrm{K}_{\text {ATP }}^{+}$channels while propofol, etomidate and midazolam have no effect on the above proteins and final myocyte survival in rat models. The effect of midazolam on sarcolemal $\mathrm{K}^{+}{ }_{\text {ATP }}$ channels activity still needs to be elucidated ${ }^{33}$.

An important regulator of cardiac function is adenosine. Its cardiac effects are predominately mediated by $A_{1}$ and $A_{2 A}$ receptors. Activation of $A_{1}$ receptors reduces oxygen demand by causing a negative chronotropic and dromotropic effect, and by inhibiting catechoamine-stimulated increases in ventricular contractility, whereas activation of $A_{2 A}$ receptors increases oxygen supply by causing coronary vasodilatation. The physiologic properties of adenosine convey cardioprotection during myocardial ischemia ${ }^{34}$. Some drugs that weakly inhibited adenosine metabolism reduced the incidence of early cardiac death and myocardial infarction after coronary artery bypass grafting $^{35}$. Benzodiazepines reduce adenosine degradation by weakly inhibiting the nucleoside transporter, the major mechanism whereby the effect of adenosine is terminated through reuptake into cells and reincorporation into the intracellular nucleoside pool. In the functional studies, benzodiazepines augmented the negative inotropic effect of exogenous adenosine in guinea pig atrial strips ${ }^{36,37}$. Binding and functional studies have been conducted in cardiac tissue for the most commonly used benzodiazepine in the perioperative setting, midazolam. Seubert et al. ${ }^{38}$ showed that midazolam selectively potentiates the $\mathrm{A}_{2 \mathrm{~A}}$ receptor-mediated effects of adenosine.

From the results of our experiment it can be deduced that the administration of midazolam in the laboratory rats has cardioprotective potential against ischemia-reperfusion induced injury in rat hearts. This effect is demonstrated in the functional parameters of hearts, LVP, LVEDP and $+\mathrm{dP} / \mathrm{dt}_{\text {max }}$

From recent studies there is increasing evidence that cardioprotection by anaesthetic agents can be elicited in the clinical setting and may add to other organ protection strategies. Thus, it is conceivable that the choice of anaesthetic drug may have an impact on patient outcome in ischemia-reperfusion situations. However, this still has to be confirmed by large studies that examine definitive outcome parameters.

\section{REFERENCES}

1. Walser A, Zenchoff G, Fryer RI. Quinazolines and 1.4-benzodiazepines.75.7-hydroxyaminobenzodiazepines and derivatives. J Med Chem 1976; 19:1378-81.

2. Skerritt JH, Johnston GA. Enhancement of GABA binding by benzodiazepines and related anxiolytics. Eur J Pharmacol 1983; 89:193-98.

3. Isojärvi JI, Tokola RA. Benzodiazepines in the treatment of epilepsy in people with intellectual disability. J Intellect Disabil Res 1998; 42:80-92.

4. Garratt JC, Gent JP, Feely M, Haigh JR. Can benzodiazepines be classified by characterising their anticonvulsant tolerance-inducing potential? Eur J Pharmacol 1988; 145:75-80.

5. Tokunaga S, Takeda Y, Shinomiya K, Hirase M, Kamei C. Effects of some H1-antagonists on the sleep-wake cycle in sleep-disturbed rats. J Pharmacol Sci 2007; 103:201-6.

6. Kozlovski VI, Vdovichenko VP, Chlopicki S, Malci SS, Praliyev ZD, Zcilkibayev OT. Antiarrhytmic profile and endothelial action of novel decanhydroquinoline derivatives. Pol J Pharmacol 2004; 56:767-74.

7. Yellon DM, Downey JM. Preconditioning the myocardium: from cellular physiology to clinical cardiology. Physiol Rev 2003; 83:1113-51.

8. Vaage J, Valen G. Preconditioning and cardiac surgery. Ann Thorac Surg 2003; 75:S709-14.

9. Mullenheim J, Ebel D, Bauer M, Otto F, Heinen A, Frassdorf J, Preckel B, Schlack W. Sevoflurane confers additional cardioprotection after ischemic late preconditioning in rabbits. Anesthesiology 2003; 99:624-31.

10. Zaugg M, Lucchinetti E, Uecker M, Pasch T, Schaubb MC. Anaesthetic and cardiac preconditioning. Part I. Signalling and cytoprotective mechanisms. Br J Anaesth 2003; 91:551-65.

11. Schlack W, Hollmann M, Stunneck J, Thämer V. Effect of halothane on myocardial reoxygenation injury in the isolated rat heart. Br J Anaesth 1996; 76:860-67. 
12. Preckel B, Schlack W. Effect of anesthetic on ischemia-reperfusion injury of the heart. In: Vincent JL, ed. Yearbook of intensive care and emergency medicine. Berlin: Springer; 2002. 13 Oguchi T, Kashimoto S, Yamaguchi T, Nakamara T, Kumazawa T. Comparative effects of halothane, anflurane, isoflurane and sevoflurane on function and metabolism in the ischemic rat heart. $\mathrm{Br}$ J Anaesth 1995; 74:569-75.

14. Szekely A, Heindl B, Zahler S, Conzen PF, Becker BF. Nonuniform behavior of intravenous anesthetics on postischemic adhesion of neutrophils in the guinea pig heart. Anesth Analg 2000; 90:12931300.

15. Buljubasic N, Marijic J, Berczi V, Supan DF, Kampine JP, Bosnjak ZJ. Differential effects of ethomidate, propofol, and midazolam on calcium and potassium channel currents in canine myocardial cells. Anesthesiology 1996; 85:1092-99.

16. Galley HF, Dubbels AM, Webster NR. The effect of midazolam and propofol on interleukin-8 from human polymorphonuclear leucocytes. Anesth Analg 1998; 86:1289-93.

17. Nishina K, Akamatsu H, Mikawa K, Shiga M, Maekawa N, Obara $\mathrm{H}$, Niwa Y. The inhibitory effects of thiopental, midazolam and ketamine on human neutrophil functions. Anesth Analg 1998; $86: 159-65$.

18. Nonaka A, Kashimoto S, Imamura M, Furuya A, Kumazawa T. Mechanism of the negative inotropic effect of midazolam and diazepam in cultured foetal mouse cardiac myocytes. Eur J Anaesthesiol 1997; 14:481-87.

19. Anholt RR, De Sousa EB, Oster-Granite ML, Snyder SH. Peripheral-type benzodiazepine receptors: autoradiographic localization in whole-body section of neonatal rats. J Pharmacol Exp Ther 1985; 233:517-26.

20. De Sousa EB, Anholt RR, Murphy KMM, Snyder SH, Kuhar MJ Peripheral-type benzodiazepine receptors in endocrine organs: autoradiographic localization in rat pituitary, adrenal, and testis. Endocrinology 1985; 116:567-73.

21. Gavish M, Katz Y, Bar-Ami S, Weizman R. Biochemical, physiological and pathological aspects of the PBR. J Neurochem 1992; 58:1589-1601.

22. McEnery MW, Snowman AM, Trifiletti RR, Snyder SH. Isolation of the mitochondrial benzodiazepine receptor: association with the voltage-dependent anion channel and the adenine nucleotide carrier. Proc Natl Acad Sci USA 1992; 89:3170-74.

23. Liazun EJ, Delmas P, Shire D, Ferrara P. Topological analysis of the peripheral benzodiazepine receptor in yeast mitochondrial membranes supports a five-transmembrane structure. J Biol Chem 1998; 273:2146-52.

24. Li J, Wang J, Zeng Y. Peripheral benzodiazepine receptor ligand, PK 11195 induces mitochondria cytochrome c release and dissipation of mitochondria potential via induction of mitochondria permeability transition. Eur J Pharmacol 2007; 560:117-22.

25. Bono F, Lamarche I, Prabonnaud V, Le Fur G, Herbert JM Peripheral benzodiazepine receptor agonists exhibit potent an- tiapoptotic activities. Biochem Biophys Res Commun 1999; 265:457-61.

26. Leducq N, Bono F, Sulpice T, Vin V, Janiak P, Le Fur G, O ' Connor SE, Herbert JM. Role of peripheral benzodiazepine receptors in mitochondrial, cellular and cardiac damage induced by oxidative stress and ischemia-reperfusion. J Pharmacol Exp Ther 2003; 306:828- 37.

27. Galiegue S, Tinel N, Casellas P. The peripheral benzodiazepine receptor: a promising therapeutic drug target. Curr Med Chem 2003; 10:1563-72.

28. Semba K, Adachi N, Arai T. Facilitation of serotogenic activity and amnesia in rats caused by intravenous anesthetics. Anesthesiology 2005; 102:616-23.

29. Veselis RA, Reinsel RA, Feshchenko VA, Wronski M. The comparative amnestic effects of midazolam, propofol, thiopental, and fentanyl at equisedative concentrations. Anesthesiology 1997; 87:749-64.

30. Malagon I, Hogenbirk K, Pelt J, Hazekamp MG, Bovill JG. Effect of three different anaesthetic agents on the postoperative production of cardiac troponin $\mathrm{T}$ in pediatric cardiac surgery. Brit $\mathrm{J}$ Anaesth 2005; 94:805-9.

31. Szekely A, Heindl B, Zahler S, Conzen PF, Becker BF. Nonuniform behaviour of intravenous anesthetics on postischemic adhesion of neutrophils in the guinea pig heart. Anesth Analg 2000; 90:12931300.

32. Nishina K, Akamatsu H, Mikawa K. The inhibitory effect of thiopental, midazolam and ketamine on human neutrophil functios. Anesth Analg 1998; 86:159-65.

33. Papaioannou V, Dragoumanis CH. Molecular mechanisms of cell adaptation to hypoxia and the role of ischemic and anesthetic preconditioning. Greek Eur J Perioperative Med 2007; 5:1-10.

34. Zaugg M, Lucchinetti E, Spahn DR, Pasch T, Garcia C, Schaub MC. Differential effects of anesthetics on mitochondrial KATP channel activity and cardiomyocyte protection. Anesthesiology 2002; 97:15-23.

35. Shryock JC, Belardinelli L. Adenosine and adenosine receptors in the cardiovascular system: Biochemistry, physiology, and pharmacology. Am J Cardiol 1997; 79:2-10.

36. Mullane K. Acadesine: The prototype adenosine regulating agent for reducing myocardial ischaemic injury. Cardivasc Res 1993; 27:43-7.

37. Barker PH, Chanachan AS. Inhibition of adenosine accumulation into guinea pig ventricle by benzodiazepines. Eur J Pharmacol 1982; 78:241-44.

38. Kenakin TP. The potentiation of cardiac responses to adenosine by benzodiazepines. J Pharmacol Exp Ther 1982; 222:752-58.

39. Seubert CN, Morey TE, Martynyuk AE, Cucchiara RF, Dennis DM. Midazolam selectively potentiates the A2A- but not A1receptor-mediated effects of adenosine. Anesthesiology 2000; 92:567-77. 